\title{
Integrated Assessment: A Learning Adventure And Growth Opportunity For Adult Learners
}

H. Van Zyl, University of the Free State, South Africa Mrs. L. Massyn, University of the Free State, South Africa

\begin{abstract}
The Bachelor in Management and Leadership (BML) is a programme specifically designed for working adult learners in the field of management leadership. As part of their assessment, students have to complete a small research project, called the Major Piece of Work (MPW). The aim of this paper is to discuss the Major Piece of Work as a real example of integrated assessment in order to highlight the value of integrated assessment for adult learners. The first part of the paper comprises an explanation of the Major Piece of Work as an integrated assessment instrument, whilst the second part will focus on the results of a survey regarding the value of the Major Piece of Work highlighted by BML students.
\end{abstract}

Key words: Adult learners, assessment, integrated assessment, field study, adult learning programme, Major Piece of Work

\section{INTRODUCTION}

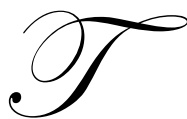

he Bachelor in Management and Leadership (BML) offered by the School of Management (University of the Free Sate, South Africa), is a unique programme within the South African context and is specifically designed for working adult learners in the field of management leadership. The programme is based on experiential learning, as well as the assessment and recognition of prior learning.

The majority of the students enter the programme at a fairly mature age. For many of them, this is the first time that they are exposed to the higher education environment. To qualify as an adult learner in South Africa, the learner must be at least 23 years of age. However, the definition of an adult learner remains a lively debate with various criteria used from country to country. For the purposes of this paper adult learners will be defined as learners older than 23 years of age, whose major role in life is something other than being a full-time student (Chickering in Cove, LaMaster \& White, 2006).

To accommodate adult learners the programme design incorporates various features unique to adult learners. First Recognition of Prior Learning (RPL) is done via the submission of portfolios after a six month course (Portfolio Development Course), after which students are provided with an opportunity to document previous coursework and learning from work experience. In this way, students can demonstrate the competencies formulated in the outcomes for each module and can earn credits without repeating learning from previous experience.

Secondly, the programme design is flexible to accommodate adult learners in terms of balancing their various life roles. Students introduced to the learning environment are afforded the opportunity to exit at different levels with an approved qualification. (Due to changes in the national policy regarding programme planning this might not be an option in the future.) The programme comprises three levels of learning - learning content on a certificate level, a diploma level and finally, the degree level. 
Another adjustment in the programme design due to the target population is the assessment methods that are used. The programme is designed to engage learners in active and collaborative (participative) learning (group work, essays, reports, simulations, debates, etc.), where assessment is based on content, work experience and relevant independent contributions. Students do not write formal summative assessments at the end of the semester (e.g. examinations). Assessments rather focus on skill development and critical thinking, and not on the regurgitation of knowledge.

Furthermore, continuous assessment that is formative in nature, forms part of the curriculum design and allows the student to learn, grow and develop throughout every module. Apart from the assessment of each module, students are also expected to produce a final Major Piece of Work (field study) in conclusion of the degree level of the programme. In this way, students are afforded the opportunity to demonstrate the integration of competencies gained throughout the programme by means of a research project, preferably based on challenges in the workplace or any other suitable topic related to the outcomes of the programme..

The aim of this paper is to discuss the Major Piece of Work (MPW) as a real example of integrated assessment, in order to highlight the value of integrated assessment for adult learners. The first part of the paper comprises an explanation of the Major Piece of Work as an integrated assessment instrument, whilst the second part will focus on the results of a survey regarding the value of the Major Piece of Work, highlighted by BML students.

\section{STRUCTURE OF THE MAJOR PIECE OF WORK}

The Major Piece of Work is the final integrated form of assessment for the BML qualification. The final product must be a demonstration of the overall outcomes of the BML programme, as well as an integration of the three domains of the programme, namely Management, Leadership and Environment. The Management domain focuses on aspects related to the field of Business Management. The Leadership domain focuses on aspects related to personal development and Industrial Psychology, while the Environment domain focuses on Economics and other related subject fields that could influence the business environment.

The Major Piece of Work is divided into related parts on the various exit levels. At the end of the certificate level every student must attend a class where an overview of the outcomes of the Major Piece of Work is given (3 credits). In addition, every student must submit a preliminary topic and research proposal. This proposal is used to allocate an academic supervisor to the student.

During the diploma level of the BML programme, every student must expand on the preliminary research proposal, which is then presented to a permanent panel of supervisors at the end of the diploma level (7 credits). The panel provides formative feedback to each student, which can be used to improve the initial MPW idea. A mark is allocated for the research proposal. From 2007 additional sessions, focusing on the basics of research methodology, have also been offered to students by one of the permanent panel members.

The third part of the MPW consists of preparing and submitting the final document, as well as a final presentation of the MPW in conclusion of the degree level. This process, up to the final presentation, is formative in nature and gives the student the opportunity to grow and develop throughout the BML programme. The structure of the MPW equips the student with skills to prepare and present the final product.

Students are assisted by three key role-players throughout the process, namely the academic advisor, the supervisor and a mentor from the work place. The main role of the academic advisor is to act as a sounding board should the student need moral support and encouragement in preparation of the MPW. The academic advisor also provides general support. The academic supervisor guides the student through the academic research process and assists the student in preparing the final product, and the two presentations. The mentor assists with the practical side of the project and empowers the student from a work perspective in conducting the project. 


\section{THE MAJOR PIECE OF WORK AS AN INTEGRATED ASSESSMENT}

According to SAQA (2005) integrated assessment can be defined as: "A form of assessment which permits the learner to demonstrate applied competence and which uses a range of formative and summative assessment methods". Given that the BML programme is an outcomes-based programme with an experiential learning philosophy, students have the opportunity to gradually obtain skills, knowledge and attitudes in a theoretical and practical way during the programme and are assessed accordingly. The same approach applies to the Major Piece of Work, which is an integrated assessment combining theoretical knowledge with practical applications to develop values and attitudes and integrating the three domains (Environment, Management and Leadership) of the BML programme.

Three competencies are assessed by the Major Piece of Work, namely foundational competencies, practical competencies and reflective competencies.

1. The foundational competencies correspond with the outcome of the programme where students are expected to correctly use terminology, definitions and theory referring to management and leadership (BML Learning Guide, 2007). These competencies entail the knowledge base of the field in which the Major Piece of Work is conducted.

2. The technical competencies refer mainly to a demonstration and understanding of the techniques and strategies involved in analytical (theoretical) enquiry and problem-solving, and to synthesise and critically evaluate management leadership information (BML Learning Guide, 2007). These competencies are based on the practical skills acquired within the field in which the Major Piece of Work is conducted.

3. The reflective competencies mirror the outcome of the programme, requiring students to understand the role of the managerial leader in society (BML Learning Guide, 2007). The outcome focuses on the values and attitudes that are fostered and developed in students.

The SAQA document (2005) provides clear guidelines of what should be included in integrated assessment. Firstly, a number of outcomes and assessment criteria would be assessed together. In the Major Piece of Work, not only are foundational competencies (in terms of the applicable theory) assessed, but the focus is also on the achievement of technical competencies (demonstration of practical skills and application of theory in the workplace) and most importantly, reflective competencies.

Furthermore, a number of assessment methods are used to measure the outcomes. In the Major Piece of Work students have to present a written report in various forms; a one-page proposal document and, later on, a final research report. In addition, they have to present their preliminary proposal and final document orally to a panel that assesses all three competencies - namely foundational, technical and reflective.

SAQA further states that integrated assessment will allow the "collecting of natural occurring evidence" and also "acquiring evidence from other sources such as a supervisor's reports, testimonials, portfolios of work previously done, logbooks, journals etc". Normally the topics for the Major Piece of Work are based on authentic situations, challenges and/or problems in the workplace of the students. The research that is done must have a theoretical foundation, integrating the different disciplines of the BML programme with the practical challenges and problems encountered in the workplace. Examples of some of the topics of the final presentations are:

- $\quad$ The development of a stress management programme for traffic officers

- $\quad$ Stress of employees in Telkom Prepaid Call Centre

- A profitability model for the regional sales offices of FNB Home Loans

The following topics are examples of what students would like to work on (these topics are to be refined further after the first presentations):

- $\quad$ The effects of rising inflation on the different market segments in South Africa

- $\quad$ Public participation for the success of community development

- $\quad$ Reward and recognition programme at Standard Bank 
In many instances, after completion of the MPW, students approach their heads of departments or management teams with the recommendations from their studies. The students have the opportunity to demonstrate their skills, knowledge and values obtained during the BML with the MPW. The MPW encourages the students to become problem-solvers. In addition, the student adds value in his/her work environment. The MPW as an integrated assessment is about learning, and applying the learning. It forms an integral part of the teaching and learning process within the BML programme.

\section{VALUE OF THE MAJOR PIECE OF WORK AS EXPERIENCED BY STUDENTS}

In order to understand students' attitudes regarding the Major Piece of Work, and to identify the value of the MPW to students, a survey was sent electronically to all students that completed the BML (and thus their MPW) at the end of 2007. Of the 49 students, 25 students responded to the request. That is a response rate of $51 \%$. The survey consisted of biographical information and questions regarding students' opinion on the MPW. Regarding the gender of the students who responded to the survey almost half were female (41\%) and 59\% were male. Almost two-thirds of the students were married (66\%). In terms of race, the results indicated that almost half of the students who completed the survey were white, with $38 \%$ black and $10 \%$ coloured. This is also a close reflection of the total student population who completed the BML in 2007.

Most of the respondents (14 or 56\%) were between 36 to 45 years of age. Most of the students (72\%) have children en $82 \%$ of those with children are still supporting their children financially. Figure 1 also indicates the obligations of students. If one considers the definition of adult learners as mentioned earlier in this paper, it is clear that all respondents qualify as adult learners, being older than 23 years of age and having obligations other than being a student.

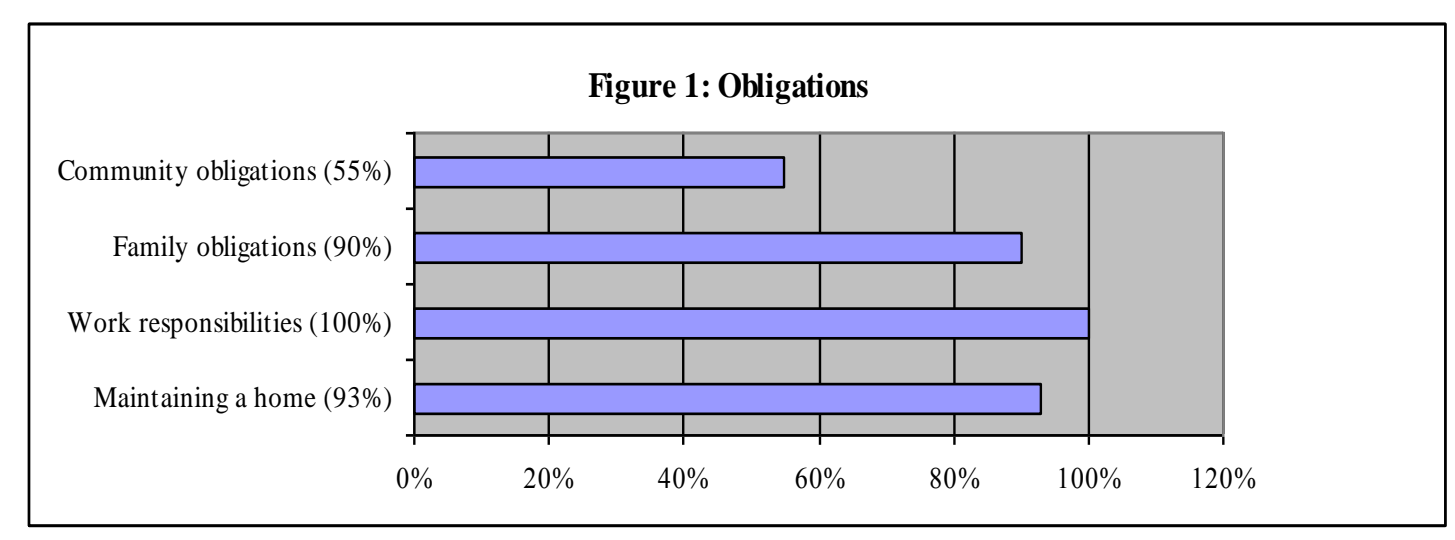

Most of them are working in the private sector $(72 \%)$, in the business and commerce sector (59\%) and the services sector $(24 \%)$. Most of the respondents are also in middle management positions (44\%). Twenty-one of the respondents are in a management position (entry management $-36 \%$ ) and (top management - 4\%). Not one of the questions in the survey prompts students to indicate if they were promoted after completing the BML, however, informal conversations with students quite often reveal that they are promoted while completing the BML. 


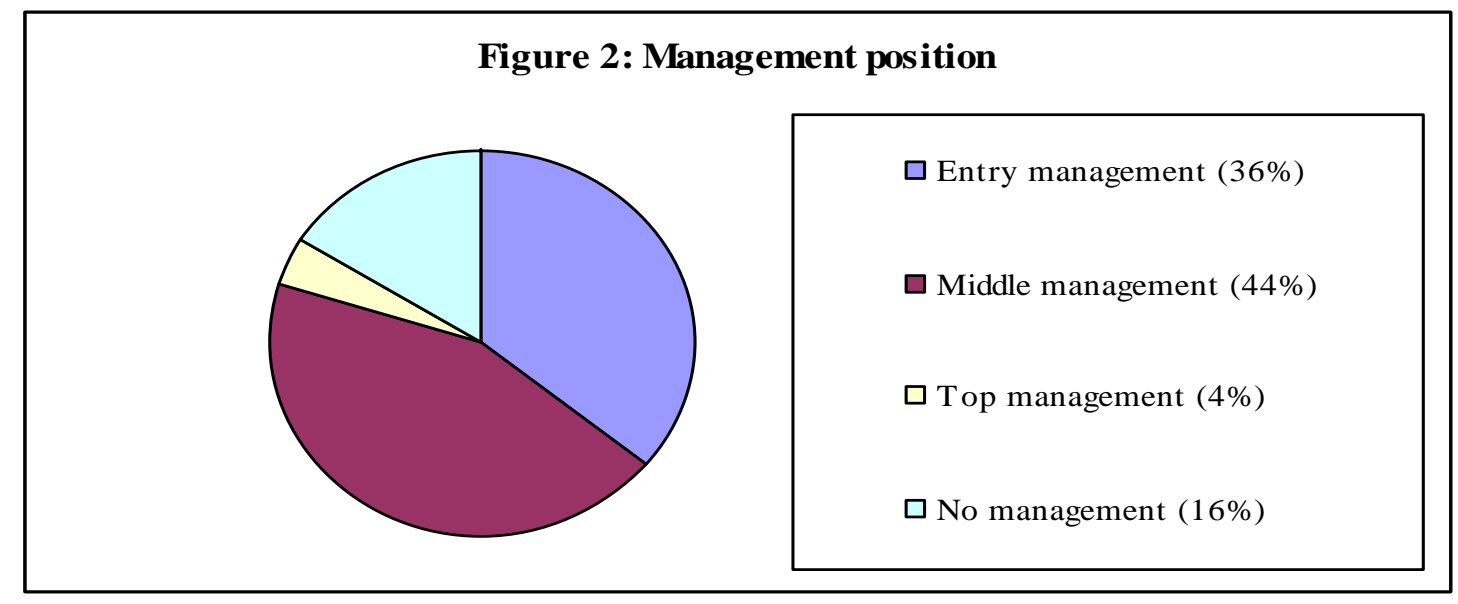

Most students are considering further education (48\%) while $48 \%$ are currently enrolled for some form of education. Only $16 \%$ are not currently enrolled for any education (Figure 3). Students are sensitised during the BML on the need to continuously update their skills.

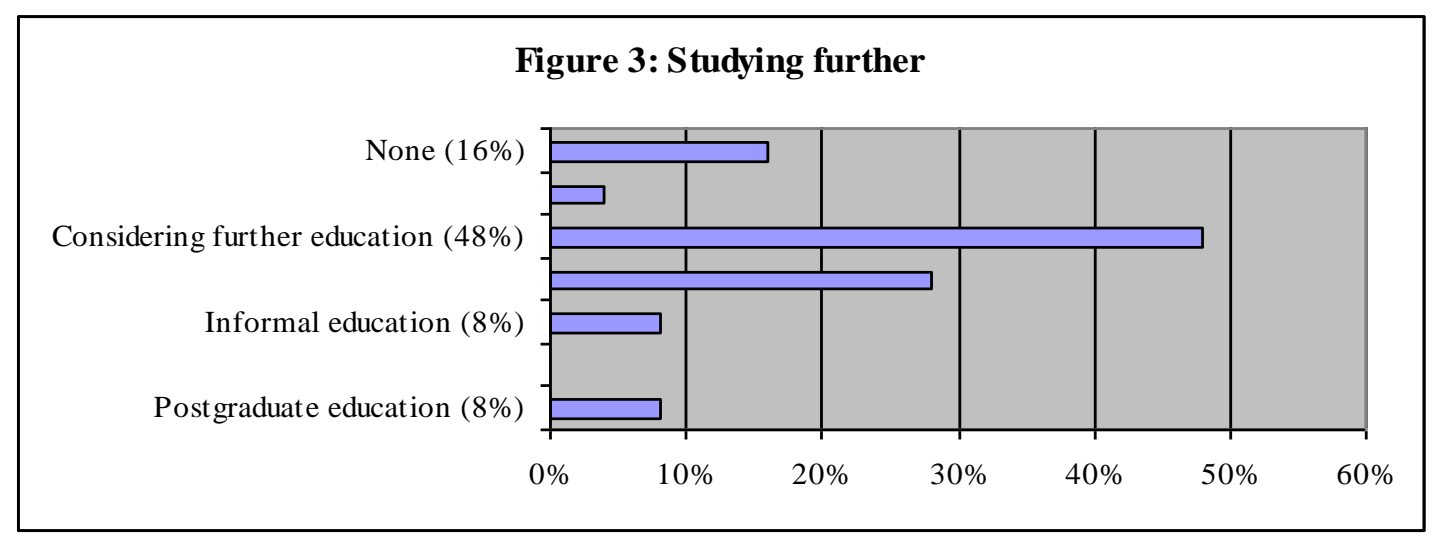

Students were asked to reflect on the various aspects that integrated assessment entails. Their responses regarding these aspects are summarised in Table 1. Students generally agree with the statements regarding how integrated assessment should look. They feel that the MPW is an integral part of the BML and that a number of outcomes are assessed together. Not all of them felt that a combination of assessment methods was used (4\%) although the majority agreed with this statement. Students felt that the MPW forced them to integrate the three domains $(84 \%)$.

Table 1: Student opinions on integrated assessment

\begin{tabular}{|c|c|c|c|c|c|c|}
\hline & $\begin{array}{c}\text { Totally } \\
\text { disagree }\end{array}$ & Disagree & Neutral & Agree & $\begin{array}{c}\text { Totally } \\
\text { agree }\end{array}$ & N/A \\
\hline The MPW is a crucial part of the BML programme. & $0 \%$ & $0 \%$ & $4 \%$ & $32 \%$ & $64 \%$ & $0 \%$ \\
\hline The MPW assesses a number of outcomes together. & $0 \%$ & $0 \%$ & $0 \%$ & $40 \%$ & $60 \%$ & $0 \%$ \\
\hline The MPW consists of a combination of assessment methods. & $0 \%$ & $4 \%$ & $4 \%$ & $32 \%$ & $60 \%$ & $0 \%$ \\
\hline The MPW forced me to integrate the three domains. & $0 \%$ & $0 \%$ & $4 \%$ & $12 \%$ & $84 \%$ & $0 \%$ \\
\hline
\end{tabular}


Regarding students learning from the MPW (Table 2) they felt that the MPW added value to their learning in the BML (96\%) and, more importantly, they also reported that they applied the knowledge that they gained in the MPW (96\%). In terms of the reflective value of the MPW all students agreed that the MPW forced them to reflect on their learning in the BML. They also agreed that the MPW integrated the skills, knowledge and attitudes that they have acquired in the BML (100\%).

Table 2: Students' learning from the MPW

\begin{tabular}{|c|c|c|c|c|c|c|}
\hline & $\begin{array}{l}\text { Totally } \\
\text { disagree }\end{array}$ & Disagree & Neutral & Agree & $\begin{array}{l}\text { Totally } \\
\text { agree }\end{array}$ & N/A \\
\hline I feel the MPW added value to my learning. & $0 \%$ & $0 \%$ & $4 \%$ & $28 \%$ & $68 \%$ & $0 \%$ \\
\hline $\begin{array}{l}\text { I have applied some of the knowledge that I have gained in } \\
\text { the MPW. }\end{array}$ & $0 \%$ & $0 \%$ & $4 \%$ & $16 \%$ & $80 \%$ & $0 \%$ \\
\hline $\begin{array}{l}\text { The MPW forced me to reflect on previous learning in the } \\
\text { BML. }\end{array}$ & $0 \%$ & $0 \%$ & $0 \%$ & $8 \%$ & $92 \%$ & $0 \%$ \\
\hline The MPW integrates skills, knowledge and attitudes. & $0 \%$ & $0 \%$ & $0 \%$ & $16 \%$ & $84 \%$ & $0 \%$ \\
\hline
\end{tabular}

The last few questions (Table 3) reflected on the role of the three support functions utilise in the MPW. Most students agreed (72\%) that their academic supervisor played a crucial part in the MPW process, while 20\% preferred to stay neutral regarding this question. Regarding the academic advisor, $80 \%$ felt that the academic advisor supported them and are important to the MPW process, while there were mixed results regarding the support of the mentor. More than half of the students (52\%) felt that the mentor was important, while $20 \%$ preferred not to comment, and 24\% felt that the mentor was not that important in the MPW.

Table 3: Students' opinion on the support received

\begin{tabular}{|c|c|c|c|c|c|c|}
\hline & $\begin{array}{c}\text { Totally } \\
\text { disagree }\end{array}$ & Disagree & Neutral & Agree & $\begin{array}{c}\text { Totally } \\
\text { agree }\end{array}$ & N/A \\
\hline $\begin{array}{l}\text { My academic supervisor played a crucial part in the MPW } \\
\text { process. }\end{array}$ & $0 \%$ & $8 \%$ & $20 \%$ & $28 \%$ & $44 \%$ & $0 \%$ \\
\hline $\begin{array}{l}\text { The academic advisor played a crucial part in the MPW } \\
\text { process. }\end{array}$ & $0 \%$ & $4 \%$ & $17 \%$ & $38 \%$ & $42 \%$ & $0 \%$ \\
\hline My mentor played a crucial part in the MPW process. & $0 \%$ & $24 \%$ & $20 \%$ & $20 \%$ & $32 \%$ & $0 \%$ \\
\hline
\end{tabular}

At the end of the survey a few open questions were asked. Firstly, students were asked to identify positive and negative aspects regarding the MPW. They also had to identify the skills and qualities that they developed through the MPW. Finally they were given the opportunity to make suggestions to improve the MPW process. From experience, the involvement of the mentor depends on the students. Some students consult their mentors on a regular basis while some prefer to work with relatively little involvement from their mentors. Although students are encouraged to involve their mentors in their MPW, they are not penalised if they prefer not to have a close relationship with their mentors.

Most of the students responded to the open questions. The following was perceived by students as positive regarding the MPW.

Twelve students (38\%) felt that the development of research skills was one of the positive outcomes of the MPW. In light of the fact that the BML programme is an undergraduate programme, the rest of the programme do not focus as much on the development of research skills. The MPW is the only area where they really find an opportunity to develop and apply research skills. learning are:

Students also indicated that they learnt new "things" in the MPW. Examples of their responses of the new 
"Allowed for an idea to be turned into reality."

"The opportunity to tell your story, to be able to present what you truly believe and understand and still defend it."

"It opened my eyes to see the workplace in a different perspective."

Students also see the integration of the three domains and the integration of theory and practice as a positive outcome of the MPW (22\%). The rest of the positive aspects identified by students are summarized in Table 4.

Table 4: Positive aspects of the MPW

\begin{tabular}{|c|c|c|}
\hline & $\%$ & $\mathbf{N}$ \\
\hline Research skills improved & $38 \%$ & 12 \\
\hline Learnt new things & $22 \%$ & 7 \\
\hline An opportunity to integrate various aspects & $22 \%$ & 7 \\
\hline Skills where improved: Presentation skills & $9 \%$ & 3 \\
\hline : Interpersonal communication & $6 \%$ & 2 \\
\hline Application to the workplace & $3 \%$ & 1 \\
\hline & $100.00 \%$ & 32 \\
\hline
\end{tabular}

Regarding negative aspects, $30 \%$ of students indicated that they would prefer if they could only work on the MPW instead of doing it with other modules. The programme takes the average student about four and a half years to complete, and the final presentation is scheduled at the end of the course. Students can, however, opt to leave the MPW and enroll only for the MPW during the following semester. However, because they are in cohort groups, the group puts pressure on students to complete the MPW together. Students also indicate that they did not receive enough support from supervisors $(25 \%)$. After further analysis it came to the attention of the researchers that the supervisors in question were not full-time academics, and therefore were not that informed regarding the MPW and the research process. They were part of a pilot project that has since been phased out. Since 2007 all supervisors must have academic experience and have to attend compulsory training sessions.

Some comments from students regarding the expectations and time constraints:

Initially it appeared as though there was no set structure on what has to be done. As a result, I could not really know where to run and how I should run. I did not even understand what was expected of me as a student. That changed two years into the programme and only then I started enjoying the process since I had direction.

The comment illustrates the uncertainty of students related to the MPW. The other modules in the programme are very structured and students know exactly what is expected of them. Selecting a research topic in their first year is quite a challenge to students who have never been in higher education.

The time factor was very hectic given that I have to maintain normal work home etc functionalities.

Table 5: Negative aspects of the MPW

\begin{tabular}{|c|c|c|}
\hline & $\%$ & $\mathbf{N}$ \\
\hline Time constraints & $30 \%$ & 6 \\
\hline Supervisor support not sufficient & $25 \%$ & 5 \\
\hline Information regarding research & $10 \%$ & 2 \\
\hline Struggle to integrate various aspects & $10 \%$ & 2 \\
\hline Not sure what was expected & $10 \%$ & 2 \\
\hline Presentation & $5 \%$ & 1 \\
\hline Provide better feedback & $5 \%$ & 1 \\
\hline More information regarding the topic & $5 \%$ & 1 \\
\hline & $100.00 \%$ & 20 \\
\hline
\end{tabular}


Regarding the question on the skills and qualities they developed, most students indicated academic skills, such as research skills, thinking skills and also more practical generic skills related to the programme, like presentation skills. A summary of these skills and the response rate are shown in table 6.

Table 6: Skills and qualities learnt from the MPW

\begin{tabular}{|c|c|c|}
\hline & $\%$ & $\mathbf{N}$ \\
\hline Research skills & $11.765 \%$ & 6 \\
\hline Writing skills & $11.765 \%$ & 6 \\
\hline Presentation skills & $11.765 \%$ & 6 \\
\hline $\begin{array}{l}\text { Conceptualization, lateral thinking, to formulate a logical argument, to see the big } \\
\text { picture, problem solving skills }\end{array}$ & $9.804 \%$ & 5 \\
\hline Analytical thinking skills & $9.804 \%$ & 5 \\
\hline Knowledge & $7.843 \%$ & 4 \\
\hline Integration skills & $5.882 \%$ & 3 \\
\hline Application skills & $5.882 \%$ & 3 \\
\hline Patience & $3.922 \%$ & 2 \\
\hline Wisdom & $1.961 \%$ & 1 \\
\hline Coping without sleep & $1.961 \%$ & 1 \\
\hline Resilience & $1.961 \%$ & 1 \\
\hline Reading skills & $1.961 \%$ & 1 \\
\hline Reflection & $1.961 \%$ & 1 \\
\hline Time management & $1.961 \%$ & 1 \\
\hline Discipline & $1.961 \%$ & 1 \\
\hline Interpersonal skills & $1.961 \%$ & 1 \\
\hline Servant leader & $1.961 \%$ & 1 \\
\hline Assertiveness & $1.961 \%$ & 1 \\
\hline Project management skills & $1.961 \%$ & 1 \\
\hline & $100.00 \%$ & 51 \\
\hline
\end{tabular}

Suggestions for improvements are summarised in Table 7. Regarding improvements to the MPW, 22\% pointed out the time constraints, as well as a need for better supervisors and guidance. Some if the issues identified by the students were also identified by the management team of the programme, and the following improvements were implemented in 2007:

- $\quad$ Fourteen hours of formal contact sessions on research and how to do research

- A training workshop for supervisors

- In the past the programme was also offered at some workplaces with their own facilitators, but this has changed and all students now come to the campus

Table 7: Suggestions to improve the MPW

\begin{tabular}{|c|c|c|}
\hline & $\%$ & $\mathbf{N}$ \\
\hline Dedicated time period to complete MPW & $22.22 \%$ & 4 \\
\hline Better support from supervisors & $22.22 \%$ & 4 \\
\hline Better guidance & $16.67 \%$ & 3 \\
\hline Integration & $11.11 \%$ & 2 \\
\hline More information on how to do research & $11.11 \%$ & 2 \\
\hline More collaboration between students & $5.56 \%$ & 1 \\
\hline Provide examples of topics before a topic is chosen & $5.56 \%$ & 1 \\
\hline \multirow[t]{2}{*}{ Use senior members to become involved in BML } & $5.56 \%$ & 1 \\
\hline & $100.00 \%$ & 18 \\
\hline
\end{tabular}




\section{CONCLUSION}

The aim of this paper was to discuss the Major Piece of Work (MPW) as a real example of integrated assessment, in order to highlight the value of integrated assessment for adult learners. The feedback from the adult learners who completed the BML programme in 2007 - and thus their MPW - show that students are generally positive regarding the MPW. The programme was designed in such a way that the MPW forms the capstone of the work done in the BML programme. Students view the MPW also in this light. Students indicated that they learnt and reflected in the MPW and felt that it added to their learning experience. Students also revealed that the support provided in the programme in the form of academic supervisors, academic advisors and mentors formed a crucial part in the learning process. From the student evaluation it is clear that the MPW as an integrated assessment tool reached its goal in adding value to students' learning experience.

\section{AUTHOR INFORMATION}

Helena van Zyl holds a D.Com from the University of the Free State. Currently she is the Director of the School of Management at the University.

Apart from her academic responsibilities Helena serves on several university and faculty management committees. The University awarded her a centenary medal for her outstanding role as a member of the turn-around team, which turned around the financial position of the University of the Free State, as well as her pioneering role as a woman in a senior management position at the School of Management. In addition, the Alumni Society of the University gave her a management award for her exceptional service to the University of the Free State in view of her managerial role in expanding and developing the School of Management.

She also served on the Standing Committee for the Revision of the Banks' Act (SA Reserve Bank) from 2002 -2007.

Liezel Massyn holds a Master's degree in Counselling Psychology and Higher Education and is currently busy with a PhD in Higher Education. She is the Teaching and Learning Manager in the faculty of Economic and Management Sciences at the University of the Free State, where she is responsible for amongst others innovation in teaching and learning and academic staff development in the faculty. Apart from her academic responsibilities she serves on several university and faculty committees.

\section{REFERENCES}

1. BML programme. 2007. Learning Guide. University of the Free State, Bloemfontein.

2. Cove, J. LaMaster, C. \& White, S. 2006. Staff development: Adult characteristics. Retrieved on 10 April 2008 at http://ed.fnal.gov/lincon/staff_adult.shtml

3. SAQA. 2005. Guidelines for integrated assessment. Pretoria. 
NOTES 